\title{
PENGGUNAAN E-MAGAZINE SEBAGAI BENTUK PUBLIC RELATIONS 2.0 BAGI HUMAS PERGURUAN TINGGI
}

\author{
Theresia Intan Putri Hartiana \\ Fakultas Ilmu Komunikasi Universitas Katolik Widya Mandala Surabaya
}

\begin{abstract}
ABSTRAK
Pertumbuhan Internet, menuntut praktisi Humas untuk mengembangkan media komunikasi humas yang digunakan. Begitupula bagi praktisi humas pendidikan Universitas Katolik Widya Mandala (UKWSM). E-magazine, adalah salah satu bentuk house journal berbentuk majalah elektronik yang dikembangkan humas UKWMS sejak Agustus 2013. tulisan ini akan mengkaji : 1). Mengapa Humas UKWMS mengubah bentuk Majalah House Journal-nya yang semula berbentuk cetak menjadi elektronik (e-magazine) 2). Bagaimanakah cara pendistribusian majalah elektronik Potentia? 3. Bagaimanakah dampak elektronik magazine (e-magazine) sebagai house journal di UKWMS. Metode yang digunakan adalah studi kasus dengan teknik pengambilan data dengan wawancara mendalam.
\end{abstract}

Kata-kata kunci: Public relations 2.0, jurnal internal, majalah elektronik, perguruan tinggi

\section{THE USE OF E-MAGAZINE AS A FORM OF PUBLIC RELATIONS 2.0 FOR} HIGHER EDUCATION PUBLIC RELATIONS OFFICER

\begin{abstract}
The growth of the Internet requires PR practitioner to develop their media of PR communication. Public Relations Officer of Widya Mandala Catholic University (WMCUS) is required to do the same thing. E-magazine is one of the media that Public Relations Officer Of WMCUS published since Agustus 2013. This article will examines: 1) Why Public Relations Officer of Widya Mandala Catholic University convert their printed house journal into electronic house journal. 2) How they distribute e-magazine? 3. How does the impact of house journal in the form of electronic magazine (E-magazine) in WMCUS. The method used in this research is case study with in-depth interviews as data collection techniques.
\end{abstract}

Keywords : Public relations 2.0, house journal, e-magazine, higher education

Korespondensi: Theresia Intan Putri Hartiana, S.Sos. Fakultas Ilmu Komunikasi Universitas Katolik Widya Mandala Surabaya, Jl. Dinoyo 48A, Surabaya: East Java 60265 Email: theresiaintan2502@gmail.com 


\section{PENDAHULUAN}

Saat ini pertumbuhan Internet secara tidak langsung juga menuntut praktisi Humas untuk mengembangkan media komunikasi yang dimilikinya. Sebab, setidaknya ada 3 perubahan cara Public Relations bekerja sejak kehadiran Internet. Pertama, Internet mengubah cara orang memperoleh informasi dari organisasi. Kedua, komunikasi tidak lagi bersifat top-down atau bersumber dari satu pihak ke banyak pihak, namun lebih pada komunikasi berjaringan. Ketiga, pemanfaatan Internet memunculkan adanya interaksi di antara organisasi dengan publiknya (Lattimore, 2010). Pemanfaatan Internet dalam ranah Public Relations inilah oleh Brian Solis dan Deirdre Breakenridge, disebut sebagai Public Relations 2.0 (Breakenridge: 2009).

Menyadari akan perkembangan Internet tersebut, Humas Universitas Katolik Widya Mandala Surabaya (UKWMS), sebagai lembaga di lingkungan Universitas yang bertanggung jawab atas pembentukan dan pengembangan pencitraan UKWMS secara efektif, sistematis, dan efisien (UKWMS, 2011). Sejak Agustus 2013 Humas UKWMS mengubah format Majalah House Journal-nya yang semula berbentuk cetak menjadi elektronik magazine (E-magazine) dengan nama POTENTIA.

Di lingkungan Perguruan Tinggi di Surabaya, Electronic House Journal juga dibuat oleh Universitas Ciputra dengan nama "UC Online", yang mengulas tidak hanya mengenai berbagai macam kegiatan dan informasi seputar kegiatan kampus Universitas Ciputra, namun juga berbagai macam informasi mengenai entrepreneurship atau kewirausahaan. Sehingga dalam suatu publikasi di Harian Surya, POTENTIA

1 Penyebutan istilah pemanfaatan Internet dalam Public Raletions ini beraneka macam: Brian Solis dan Deirdre Breakenridge meyebutnya sebagai Public Relations 2.0 sementara Bob Julios Ongo menyebutnya sebagai Cyber PR atau E-PR. Namun pada intinya semua mengarah pada pemahaman pemanfaatan teknologi Internet bagi Public Relations. Lebih lanjut dalam buku Putting the Public Back in Public Relations, Brian Solis dan Deirdre Breakenridge mengungkapkan Public Relations 2.0, lahir dengan melihat perkembangan bagaimana Internet merubah cara Public Relations perusahaan berkomunikasi langsung dengan publiknya. Melalui website, social media, forum online, blog, perusahaan mampu mempublikasikan, berbagi pesan perusahaan kepada orang-orang yang akan menjadi influencer. dianggap sebagai majalah elektronik pertama Universitas yang khusus mengupas kehidupan kampus. (Budiharjo, 2014)

Tulisan ini akan dikaji mengenai: 1). Mengapa Humas UKWMS mengubah bentuk Majalah House Journal-nya yang semula berbentuk cetak menjadi elektronik magazine (e-magazine) 2). Bagaimanakah cara pendistribusian majalah elektronik Potentia? 3). Bagaimanakah dampak elektronik magazine (e-magazine) sebagai house journal di UKWMS

\section{METODE PENELITIAN}

Metode dalam penelitian ini menggunakan studi kasus dengan memusatkan pada satu kasus (single case). Teknik pengumpulan data menggunakan wawancara mendalam (in-depth interview) bersifat semi terstruktur agar informan dapat lebih terbuka mengemukakan ide, dan pendapatnya (Creswell, 1998).

\section{HASIL DAN PEMBAHASAN}

Pada awalnya, house journal yang dibuat oleh Tim Humas UKWMS tampil dalam bentuk cetak dengan nama Warta Widya Mandala yang diterbikan setiap tiga bulan sekali dan distribusikan kepada seluruh civitas academica dan pihak terkait lainnya di lingkungan UKWMS. Informasi yang ditampilkan di berupa berita kegiatan, prestasi, yang dicapai oleh dosen, mahasiswa dan fakultas - fakultas yang ada di lingkungan Universitas Widya Mandala Surabaya. (Wiyani, 2014)2. Perkembangan bentuk house journal yang dibuat oleh Tim Humas Universitas Widya Mandala Surabaya, sejak Agustus 2013 mengalami perubahan, yang semula berbentuk cetak menjadi elektronik magazine (e-magazine) dengan nama Potentia sejak Agustus 2013.

Sekitar tengah tahun, kami mendapatkan banyak masukan tentang warta widya mandala, sehingga kami mencoba mencari solusi atas berbagai macam kritikan tersebut, format seperti apa yang memungkinkan. Baru Agustus 2013 kami berani memutuskan untuk

2 Hasil wawancara dengan Head of Public Relations Universitas Widya Mandala Surabaya tanggal 20 Februari 2014 


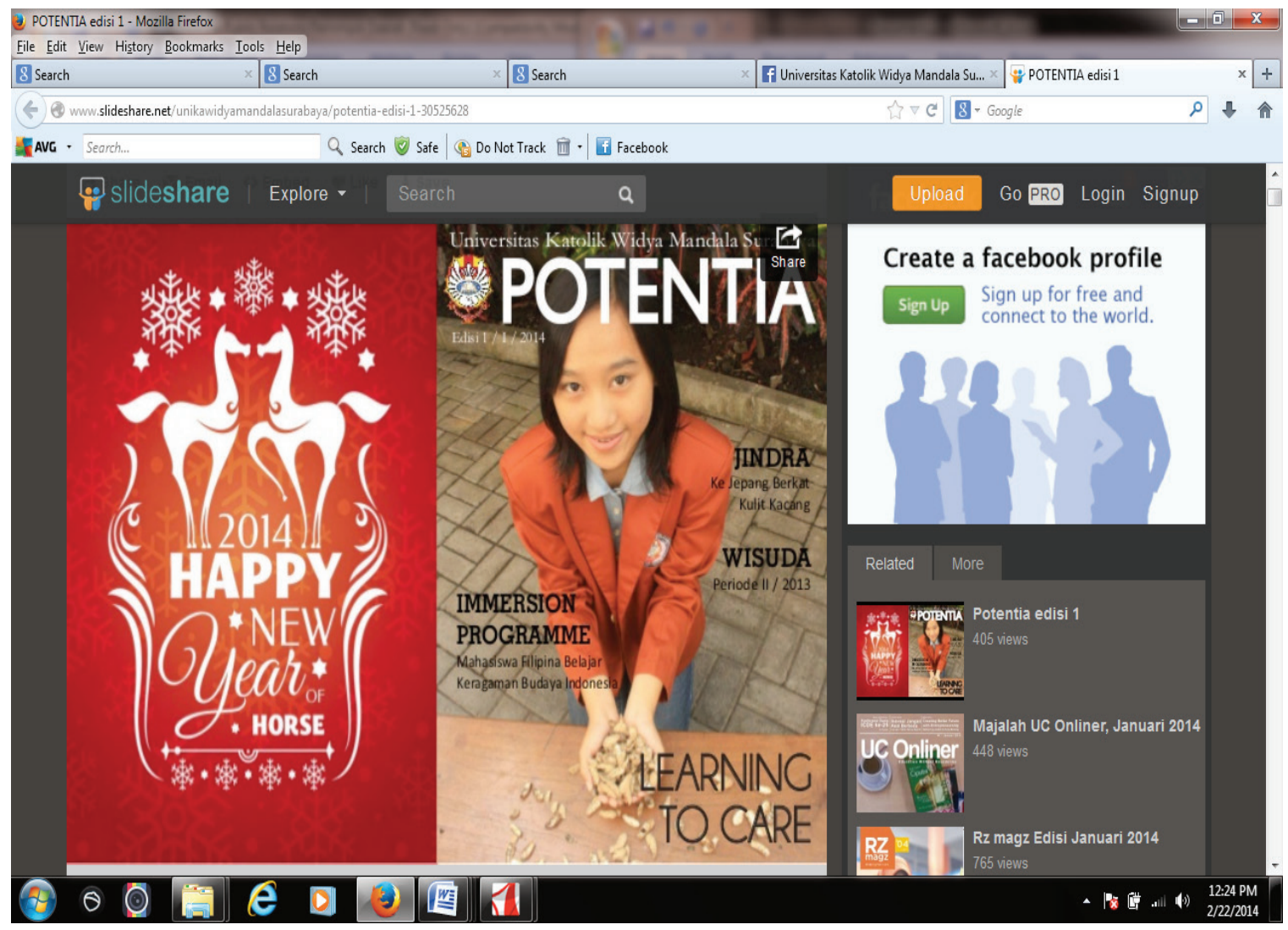

Gambar 6.1 Sampul depan House E-magazine POTENTIA

merubah ke bentuk elektronik itu. (Wiyani, 2014)

Sama halnya dengan Warta Widya Mandala sebelumnya, dalam elektronik majalah POTENTIA juga memuat mengenai berita kegiatan yang ada di lingkungan Universitas, prestasi mahasiswa dan dosen, civitas academica, seperti Lembaga Penelitian dan Pengabdian Masyarakat, Lembaga Pers Mahasiswa, Unit Kegiatan Mahasiswa. Hanya saja dalam elektronic magazine tersebut terdapat rubrik khusus yang menampilkan berita dari tiap-tiap fakultas dan unit kerja yang ada di Universitas Widya Mandala Surabaya.

Vonny Kartika Wiyani, Ketua Humas Universitas Widya Mandala Surabaya selain itu juga menyatakan:

E magazine itu sarana branding universitas yang murah meriah, selama ini kita melihat bahwa ketika bentuknya cetak banyak yang mengevaluasi, mulai dari nama hingga fungsi akhirnya., yang terkadang hanya dibuang begitu saja, kadang juga lupa dibawa pulang. Padahal kebutuhan branding dan informasi prestasi dosen, mahasiswa juga harus terus dilakukan, apalagi sekarang maraknya penggunaan gadget. Belum lagi kritikan tentang budgetnya. Jadinya dengan format baru bisa menjadi jawaban atas semua masukan. (Wiyani, 2014)

Hal tersebut juga didukung oleh Adjeng Erwita salah satu staf humas Universitas Widya Mandala Surabaya menyatakan bahwa

E magazine itu suatu bentuk inovasi dari humas WM, agar tetep dibaca publik, kita harus menyesuaikan dengan perkembangan teknologi dan jaman sekarang ini (Erwita, 2014).

Pendistribusian POTENTIA oleh Tim Humas Universitas Widya Mandala dilakukan melalui berbagai cara, misalnya saja mailing list pimpinan Universitas dan Fakultas, mailing list wartawan, social media, Facebook, Twitter, dan, website Universitas 
Bagi tim humas UKWSM dengan penggunaan e-magazine POTENTIA, dirasa mampu membawa perubahan:

Penyebarannya lebih mudah, dan tidak terbatas, kalau dengan cetak kami hanya bisa menyebarkan hanya beberapa saja. Kadang ada orang tua mahasiswa yang kuga ingin tahu perkembangan kampus, paling tidak ini bisa menjadi solusi. Konsep less paper ini juga sangat kami membantu kami. Kadang sedih juga ada yang buang - buang majalah warta widya mandala, padahal buatnya juga nga gampang (Wiyani, 2014).

Zulkarnain Nasution (2006) mengemukakan ada tiga alasan yang mendasari pentingnya peran Humas di Perguruan Tinggi: Pertama, Pengelolaan Perguruan Tinggi (rektor, pembantu rektor, dekan, pembantu dekan, senat universitas) sering menghasilkan kebijakan yang terkait pada perguruan tingginya sehingga dibutuhkan suatu bagian (dalam hal ini humas) yang secara terus menerus dan terencana mensosialisasikan, memberikan informasi kebijakan tersebut kepada masyarakat di dalam perguruan tinggi (mahasiswa, dosen, dan karyawan) dan masyarakat di luar perguruan tinggi (orang tua, mahasiswa, alumni, lembaga/ instansi lain) dan masyarakat luas.

Kedua, Persaingan yang sehat dan dinamis antar sesama perguruan tinggi di dalam negeri dan perguruan tinggi international dalam merebut minat dan calon mahasiswa, orang tua calon mahasiswa, dan masyarakat luas, membuat pimpinan perguruan tinggi dituntut menyiapkan suatu bagian (dalam hal ini Humas) untuk mengelola informasi yang jelas dan memberikan kesan citra positif.

Ketiga, Perkembangan media massa cetak dan eletronik didaerah semakin meningkat, misalnya surat kabar, radio swasta, dan televisi lokal di daerah, yang sudah pasti selalu mencari informasi yang aktual di perguruan tinggi, sebab dibutuhkan bagian Humas) untuk membina hubungan yang harmonis dengan pihak pers tersebut. Tujuan agar informasi atau berita-berita yang positif dan membangun tentang perguruan tingginya selalu menjadi bahan informasi pers itu. (Nasution, 2006)

Layaknya humas organisasi lainnya, humas pendidikan juga perlu untuk lebih peka terhadap perkembangan informasi disekitarnya. Perubahan cara berkomunikasi yang terjadi dalam masyarakat, juga perlu disiasati agar tidak ditinggalkan oleh publiknya.

Public Relations 2.0, merupakan perkembangan public relations akibat tumbuhnya Internet saat ini. Salah satu media yang dapat digunakan sebagai media informasi dan publikasi dalam kegiatan Humas Pendidikan adalah penerbitan bulletin atau warta sebagai media internal dan eksternal yang memuat berita kegiatan di lingkungan lembaganya atau disebut house journal.

E-magazine, atau majalah elektronik adalah salah satu bentuk house journal versi online dari majalah. E-zine sarat akan informasi artikel dan solusi. E-zine dapat dikatakan sebagai salah satu kendaraan E PR di dunia maya.

Melalui penggunaan E-magazine sebagai house journal akan mampu memberikan manfaat kepada praktisi humas, diantaranya: (1) Sebagai media komunikasi internal dan eksternal, (2) Media pelatihan dan pendidikan pada publik, khususnya ketika perusahaan memiliki kebijakan baru, penggunaan dapat menjadi media yang tepat bagi sosialisasi kepada karyawan. (3) Memudahkan publik untuk membaca di manapun dan kapanpun (4) Memudahlan penyebaran informasi. (5) Nilai tambah bagi tim pengelola. Persepsi yang melekat, bahwa pengelola inhouse magazine adalah bagian PR, menjadi nilai tambah bagi kinerja karyawan bagian PR dalam suatu organisasi. Sebagai pengendali arus informasi dan komunikasi membuat bagian PR selalu dibutuhkan untuk mendukung program kerja bagian lain. (6) Efisiensi dalam pembiayaan.

Berdasarkan cara pendistribusian, cara pendistribusian e-magazines juga dapat dilakukan dengan dua cara yaitu berbasis web, dan e-magazine. Berbasis Web, merupakan situs web yang berfungsi sebagai majalah, namun memberikan situs akses infromasi online kepada para pembacanya. E-magazine berbasis web ini mengharuskan para pembacanya untuk datang ke situs web tersebut, harus kemudian membaca berita dan info aktual dari halaman web ke halaman web yang lain. E magazine biasanya memiliki format dan kesan seperti majalah tradisional. Sedangkan E magazine berbasis Email, guna memudahkan pembaca untuk langsung membacanya dari inbox email mereka 
tanpa harus membuka situs webnya

Melalui penggunaan e-magazine, praktisi humas harus mampu melihat perubahan peran public yang dihadapinya. Public tidak lagi ditempatkan sebagai orang yang menggunakan jasa atau produk jasa, lebih dari itu ada perubahan tingkatan menjadi seorang publisher. Setelah menjadi publisher, seorang public akhirnya menjadi seorang influencer. Sistem komunikasi yang berubah menjadi berjaringan, menjadi public menjadikan dirinya menjadi influencer yang mampu memberikan pengaruh kepada public lainnya. Pendapat - pendapatnya yang disampaikan melalui Internet, dapat menjadi "word of mouth" yang mampu membantu meningkatkan citra perusahaan (layaknya $P u b$ lic Relations)

Hal tersebut dapat diartikan berkomunikasi melalui Internet berarti bahwa publik dari organisasi secara aktif menarik informasi tentang organisasi dari Internet, bukan organisasi yang secara aktif menyodorkan informasi. Mencari informasi sendiri apa yang dibutuhkannya tanpa harus menunggu informasi yang dibutuhkannya ada di media massa, Merubah peran publik, yang semula hanya sebagai pencari informasi, disaat itu juga dapat menjadi pemberi informasi, dengan menyebarkan informasi, seperti sosial media atau jaringan blog yang dimiliki.

\section{SIMPULAN}

Adaptasi akan perkembangan teknologi komunikasi dalam dunia public relations haruslah terus ditingkatkan agar organisasi pendidikan tidak ditinggalkan publiknya. Humas dapat menjadi agen dalam pengembagan citra perusahaan. Berbagai cara data dilakukan untuk mengembangkan media komunikasi Public Relations, salah satunya dengan mengunakan e-magazines atau majalah elektronik. Melalui e-magazines, dapat memudahkan publik untuk membaca di manapun dan kapanpun, Memu- dahlan penyebaran informasi. Nilai tambah bagi tim pengelola dan efisiensi dalam pembiayaan. Melalui sistem penyebaran berbasis web ataupun e-mail, e-magazine akan mampu membantu praktisi humas untuk menjadi "public relations" nya untuk meyebarkan informasi, karena disini e-magazines juga merubah peran publik, yang semula hanya sebagai pencari informasi ataupun pembaca, disaat itu juga dapat menjadi pemberi informasi, dengan menyebarkan informasi, seperti sosial media atau jaringan blog yang dimilikinya.

\section{DAFTAR PUSTAKA}

Breakenridge, B. S. (2009). Putting the public back in public relations: how social media is reinventing the aging business of $P R$. New Jersey: FT Press.

Breakenridge, D. (2001). Cyberbranding: brand building in the digital economy. United States of America: Prentice Hall PTR.

Budiharjo, L. (2014, Februari). Sebarkan Majalah dengan ink. Surya

Creswell, J. W. (1998). Qualitative inquiry and research design: choosing among five traditions. London: Sage Publications.

Erwita, A. (2014, Februari Sabtu). Pemaknaan POTENTIA. (T. Intan, Interviewer)

Lattimore, O. B. D. (2010). Public relations:profesi dan praktek. Jakarta: Salemba Humanika.

Nasution, Z. (2006). Manajemen humas di lembaga pendidikan. Malang: Universitas Muhammadiyah Malang.

UKWMS. (2014). Diakses 20 Februari 2014 dari http://www.slideshare.net/unikawidyamandalasurabaya/potentia-edisi-1-30525628

UKWMS. (2011). Profil UKWMS. Diakses 20 Februari 2014 dari http://www.wima.ac.id/ index.php? $\mathrm{r}=$ university/humas

Wiyani, V. K. (2014, Februari Sabtu). Pemaknaan POTENTIA. (T. Intan, Interviewer) 